
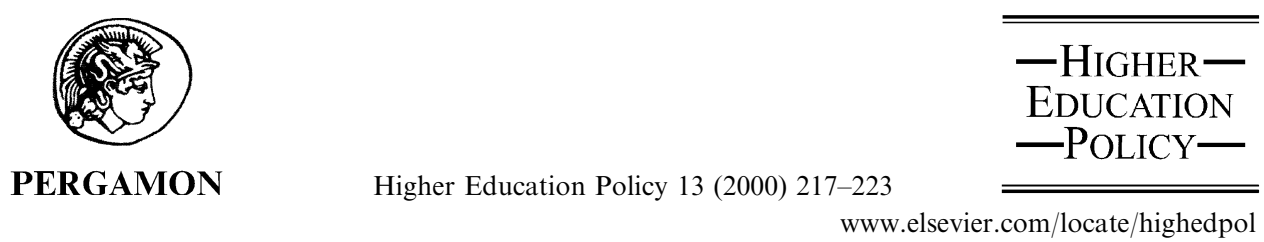

Editorial

\title{
The economy, higher education, and European integration: an introduction
}

The transformation of the national higher education system is on the political agenda in every country that takes itself seriously. For the interested observer it is clear that in the initiated transformation processes higher education receives many messages. Governmental green and white papers, new higher education laws, public debates, media coverage, all seem to point in the same direction. Higher education should "modernise", "adapt", "diversify", "marketize", it is expected to become "entrepreneurial", "competitive", more "efficient" and more "effective", more "service oriented", and more "societal relevant", while it also has to improve the "quality of its processes and products", its "relationship with the labour-market", and the "governance and management" of its institutions, the universities and colleges, to give just a few examples.

While the socio-political demands and expectations with respect to higher education have grown - especially with respect to its economic role - , in most countries the level of public funding of higher education is stagnating or even going down. This situation has led to the observation by Clark $(1998$, p. 131) that higher education suffers from a "demand overload". Many actors pour their (regularly changing!) demands in an almost constant flow on higher education and expect a rapid and fitting reaction. But are universities and colleges capable of reacting adequately? Do they have the structures, cultures, mechanisms, human and other resources that allow them to transform in the way and pace expected? In general many of the answers given to these questions seem to be rather negative. Especially the traditional research universities are regarded by some as being too conservative and passive, behaving like "dinosaurs" unaware of the meteorite that is going to hit their earth (Maassen, Neave \& Jongbloed, 1999, p. 3). The (traditional) core activities of the higher education institutions are threatened to be taken over by other (market) providers, amongst other things, because higher education is supposed to have a limited capability for dealing with the increased competition. In short, higher education is suggested to be a sector that will not survive in its present form the turbulent first decades of the new millennium, and the capabilities of adapting this form radically are regarded as being too limited.

0952-8733/00/\$20.00 C 2000 International Association of Universities. Published by Elsevier Science Ltd. All rights reserved.

PII: S0952-8733(00)00008-8 
But what do we really know about the change capacity of universities and colleges, and about the ways in which this change capacity is being used in practice? What research is being done on the dynamics of higher education? What systematic knowledge has been produced and how (if at all) is this knowledge used by practitioners at various levels, i.e. policy-makers, institutional administrators, academic leaders, etc.? Important and relevant questions, but also questions that are hard to answer. It has become a good tradition of Higher Education Policy to address these questions seriously. Examples are, for example, the double issue devoted to Markets, Higher Education and Social Responsibility, edited by David Dill (Vol. 10, 3/4, 1997) or the special issue on Diversity, Differentiation and Markets, edited by Lynn Meek, Leo Goedegebuure, and Jeroen Huisman (Vol. 13, 1, 2000). In the former a group of scholars is brought together to systematically address "the nature of market forces in their home country, how government policies are influencing these forces, and what appear to be the early effects of these policies". The latter contains papers produced as part of a longterm research project (see Meek, Goedegebuure, Kivinen \& Rinne, 1996) and presented first at an international symposium in Portugal entitled "Diversity: Market Competition or Government Intervention?" We feel privileged that we have the opportunity to add to this tradition by discussing in two special issues of Higher Education Policy (this one and number 4 later this year) the relationship between the economy, higher education, and European integration.

The contributions in the two special issues are part of an international comparative research project, HEINE, which attempts to examine in depth how European universities and colleges change concerning their economic role, and the extent to which this change is affected by governmental policies.

\section{The HEINE study "Higher education and the national economy"}

The HEINE project brought together some 30 researchers from eight countries (Austria, Belgium, Finland, Italy, the Netherlands, Norway, Portugal, and the UK). The research centers and groups involved are: AF Forum, Rome, Italy; Catholic University of Leuven, Belgium; CHEPS, University of Twente, Enschede, the Netherlands; CIPES, University of Porto, Portugal; CSET, University of Lancaster, UK; IFF, Vienna, Austria; NIFU, Oslo, Norway; University of Joensuu, Finland. The Coordinating Team of the project was formed by representatives of CHEPS, CSET and NIFU, with the overall coordination being in the hands of Peter Maassen (CHEPS), while Åse Gornitzka (CHEPS and NIFU) was the research coordinator. The project was funded by the European Commission (DG XII, TSER Programme, contract SOE2-CT97-2018), and a number of national research councils. It lasted from October 1997 to November 1999.

The main aim of the project was to examine organizational change in higher education. More specifically the research question of the project was formulated as follows: How do higher education organizations change in response to or in 
interaction with government policies and programs? We did not approach the research problem as in a classical implementation study, following a specific policy around from development and implementation to the effects of the policy in question, assuming a (linear) causal chain of events. Rather we focused on public policy initiatives as possible inputs into organisational change processes. In line with the nature of the TSER Programme it was decided to focus on changes in the economic policies and programmes of universities and colleges, assuming that an analysis of these changes would make it possible to draw general conclusions.

What do we mean by the economic role, and the economic policies and programmes of the universities and colleges? In other words, how did we operationalize the economic dimension in our study? To make this clear we want to start with discussing two rather extreme perspectives concerning the societal nature and role of higher education. Following Clark (1998), Henkel (1997) and other scholars ${ }^{1}$ the two perspectives referred to are higher education as a social institution vs higher education as an economic sector, or an industrial branch. These two perspectives each contain different suppositions with respect to: (a) the most important social functions of higher education, (b) the main problems confronting higher education, and (c) the best solutions or approaches for dealing with these problems. What do these two perspectives comprehend? According to the first perspective - viewing higher education as a social institution universities and colleges by definition must attain educational and other goals related to their core activities, retain institutional legacies, and carry out important functions for the wider society, such as the cultivation of citizenship, the preservation of an expanding cultural heritage, and the formation of characters and skills of individual students. The second perspective, i.e. higher education as an industrial branch, states that universities and colleges sell goods and services, train an important part of the workforce, and further economic development. Exposure to market forces and other competitive pressures will result in improved management, swift programmatic adaptation, maximum flexibility, and improved efficiency in the hope of enhanced "customer" satisfaction.

The tension between the two perspectives is intense. The social institution perspective is dominated by a concern that adaptation to market forces gives primacy to short-term economic demands at the neglect of a wider range of societal responsibilities, while jeopardizing the long-term public investment in higher education systems that were established for the public good. The higher education as an industrial branch perspective is dominated by a concern that higher education's inability or unwillingness to adapt will result in a loss of centrality and perhaps ultimately a loss of viability (Clark, 1998).

While the social institution perspective can be regarded as representing a "traditional" view on higher education and the industrial branch perspective a

\footnotetext{
${ }^{1}$ See, for example, various contributions to Mitra and Formica's (1997) book on University-Enterprise partnerships, or Porter's (1990) book on the competitive advantage of nations.
} 
more "modern" view, these perspectives are nonetheless indeed extremes. Obviously the HEINE study was not set up to find empirical evidence for supporting either of them. Rather than interpreting them as mutually exclusive alternatives we attempted to include both perspectives in HEINE. We assumed that the social institution perspective referred especially to the standardized, basic structures within the universities and colleges set up for performing the traditional functions of (first degree) teaching and (basic) research. The industrial branch perspective was interpreted as referring, amongst other things, to the new structures and units within universities and colleges set up to deal with "new demands and expectations", for example, in the area of life-long learning. In addition we assumed that one of the elements in the transformation of higher education of relevance is the governmental attempt to include both perspectives in the governance and decision-making bodies and structures of universities and colleges. In HEINE these three elements were used to distinguish the three clusters (see below) with respect to which we wanted to investigate "organizational change". The two perspectives are also represented in all articles included in the two special HEINE issues of Higher Education Policy.

As indicated HEINE's main funding source is the European Commission's TSER Programme. One of the underlying interests of the project concerns the way in which the emphasis of the European Commission in its programs on the economic role, that is the "higher education as an industrial branch" perspective, is contributing to the European integration, for example, with respect of the creation of one European labour market, or one open European higher education system. ${ }^{2}$ This aspect, the European integration, will be discussed in some of the contributions to the two special issues, as well as in the closing analysis of the editors.

The HEINE project consisted of three main phases. In the first (supra)national case studies focusing on specific national and EU policies and programs were undertaken. In the second in depth case studies of 40 universities and colleges in the involved countries were carried out. The final phase consisted of the comparative analyses. As referred to above the project examined organizational changes in three clusters. First, the relationship between higher education institutions and the economy in the area of regular teaching programs of universities and colleges focused on traditional students. Second, relationships between higher education teaching programs and the emerging external needs for training and education leading to new educational and training structures for "non-traditional/life-long learning students". Third, the deliberate attempts to link external stakeholders to internal structural change processes as part of the adaptation of institutional governance and

\footnotetext{
${ }^{2}$ The creation of an open European higher education system is also included as one of the main goals in the recent Sorbonne and Bologna declarations. The rationale underlying these declarations, however, can be argued to be less economically driven than the higher education programmes of the European Commission (see, for example, European Commission, 1992; Van der Wende, 2000).
} 
decision-making structures. The theoretical framework for the project was based upon two major theoretical perspectives, resource dependency and neoinstitutionalism. In addition the framework incorporated conceptualizations concerning governmental steering models. It was designed and elaborated by Åse Gornitzka (1999).

The contributions to this and the forthcoming issue of Higher Education Policy are a reflection of the first two phases of the project. To start with the main national governmental policies with respect to the economic role of higher education are presented. The difference in focus, emphasis, and explicitness between the eight countries involved will become clear as well as some of the common trends. In addition specific institutional reactions to these national policies will be discussed.

The first two contributions to this issue are by Åse Gornitzka and Peter Maassen. In their first article National Policies Concerning the Economic Role of Higher Education, they provide an analysis of the main trends over the last 15-20 years as regards the way governments in the eight countries have addressed the relationship between higher education and the economy in their national policies and programs. They discuss these trends on the basis of two dimensions: the internal vs the external dimension, and the efficiency vs the effectiveness dimension. It is argued that the cells resulting from combining these two dimensions can be used to categorize the main common issues in the national higher education policies in the eight countries. The authors conclude this article by suggesting that even though the economic role of higher education might be prominently on the policy agenda in all countries, at the same time it has become more and more difficult to separate the economic expectations and demands with respect to higher education from other societal expectations and demands. National policies address in an integrated way various interests, including economic ones. It is to a large extent up to the universities and colleges themselves to determine how much prominence they want to give to their economic role in their own policy-making processes.

In their second article, Hybrid steering approaches with respect to European higher education, Gornitzka and Maassen discuss the main developments concerning the governmental steering strategies with respect to higher education. Most analyses of the relationship between higher education and the state refer to a basic dichotomy in the state approach to steering and control. One approach emphasizing rational central planning and control and the other decentralization with indirect control based on market(like) mechanisms and self-regulation. In this dichotomy the focus is one how tight (or loose) the links between central authorities and higher education organizations are. The authors apply in their article other conceptualizations that until now have only been used incidentally in higher education research. All in all the outcome of their analyses show that the countries in question all have introduced changes in the steering relationship between higher education and the state that seem to move in the same direction, i.e. away from the state towards a greater influence of the market. Nonetheless the differences between the eight countries are of importance for trying to understand, 
for example, the way in which universities and colleges (can) adapt to changes in their environments.

In The Rise and Fall of the Private Sector in Portuguese Higher Education, Alberto Amaral and Pedro Teixeira offer a thorough analysis of a very specific national case. After the revolution of 1974 there was a pressure on the Portuguese higher education system to expand. The explicit governmental stimulation of the development and strong growth of private higher education made this expansion possible. The authors discuss how Portuguese governments used also economic arguments to justify the stimulation of the private sector. They use the recent "fall" of the private sector to illustrate the hybrid attitude of the Portuguese government with respect to state steering. On the one hand not allowing a real market to develop, but on the other hand not developing the necessary (framework) regulation to let the higher education system (including the private sector) operate effectively and efficiently.

Murray Saunders and Joan Machell provide a thorough analysis of the British developments concerning the relationship between learning and workplace experiences in Understanding Emerging Trends in Higher Education Curricula and Work Connections. British government policy over the last decade has encouraged through a range of specific funding opportunities a greater integration of curricular experiences associated with higher education with work place practices. The belief is that integration will produce a greater economic return on expenditure on higher education. Using neo-correspondence theory Saunders and Machell argue that the functionalist assumption about a tight coupling between higher education and work are incorrect. According to the authors a tight(er) coupling can only be reached through government intervention. Using empirical material from the HEINE study they suggest that a profound shift in curricular balance within higher education implying much more direct links between curricular and work experiences might be at hand.

Finally Seppo Hölttä and Pertti Malkki discuss the Response of Finnish Higher Education Institutions to the National Information Society Program. While in Portugal the economic function of the private sector is a core element in the higher education policy, and in the United Kingdom the need to improve the key professional skills of higher education graduates, in Finland the government is strongly emphasising the role of higher education in making Finland an information society. For this purpose, amongst other things, the governmental economic development policy and the higher education policy have more or less been integrated. The authors discuss this integration and provide an analysis of the reactions of universities and AMK institutions to the national government program designed to push Finland to a position of one of the world's leading high-tech countries.

Together with the eight HEINE contributions contained in the forthcoming issue of Higher Education Policy these cases serve as examples of the complexities of the changing relationship between the state and higher education. They help to understand the dynamics of higher education and the changes higher education systems, as well as individual universities and colleges are going through at the 
moment. They also help to illustrate that higher education is not a passive sector. The organisational responses to the environmental demands and expectations show that individual institutions adapt creatively to changing circumstances. As such the change processes discussed in the various HEINE contributions might be examples of higher education's continuous adaptation capacity instead of illustrations of time-bounded, externally initiated transformation processes.

\section{References}

Clark, B. R. (1998). Creating entrepreneurial universities. Organizational pathways to transformation. Oxford: Pergamon Press.

European Commission. (1992). Advanced training for competitive advantage. Communication from the Commission to the Council and the European Parliament concerning European Higher EducationIndustry Co-operation. European Commission, Brussels, 9 December.

Gornitzka, Å. (1999). Governmental policies and organisational change in higher education. Higher Education, 38, 5-31.

Henkel, M. (1997). Academic values and the university as corporate enterprise. Higher Education Quarterly, 51, 134-143.

Maassen, P., Neave, G., \& Jongbloed, B. (1999). Introduction. Organisational adaptation in higher education. In B. Jongbloed, G. Neave, \& P. Maassen, From the eye of the storm. Higher education's changing institution (pp. 1-12). Dordrecht: Kluwer Academic.

Meek, V. L., Goedegebuure, L., Kivinen, O., \& Rinne, R. (1996). The mockers and mocked: comparative perspectives on diversity, differentiation and convergence in higher education. Oxford: Pergamon Press.

Mitra, J., \& Formica, P. (1997). Innovation and economic development. University-enterprise partnerships in action. Dublin: Oak Tree Press.

Porter, M. E. (1990). The competitive advantage of nations. London: Macmillan.

van der Wende M. C. (2000). The Bologna Declaration: enhancing the transparency and competitiveness of European higher education. Paper presented at the Fourth Annual Conference of the Global Alliance for Transnational Education (GATE) Melbourne, Australia. Submitted for publication to Higher Education in Europe, CEPES.

Åse Gornitzka*

Peter Maassen

CHEPS, Center for Higher Education Policy Studies, University of Twente, P.O. Box 217, 7500 AE Enschede, The Netherlands

* Corresponding author. 